\title{
THE SIGNIFICANCE AND TREATMENT OF HYPERTENSION DURING ANAESTHESIA
}

\author{
J. W. R. MCINTYRE, F.F.A.R.C.S., D.A.
}

CiRCULATORY HOMEOSTASIS during anaesthesia is of great importance and every effort is made to maintain it. This is more commonly directed at àvoiding extreme hypotension then hypertension, though the latter can be jüst as seŕious a phenomenon, ${ }^{1,10}$ a fact illustrated by the case reported here.

A weatherbeaten man of 62 years of age, $5 \mathrm{ft}$. 4 in. in height, ànd weighing $179 \mathrm{lb}$.; was admitted for repair of a right inguinal hernia which had occurred four years previously during a tug-of-war. His exercise tolerance was still good in spite of many years' history of mild chronic bronchitis. On examination his chest was emphysematous in appearance, blood pressure taken on two occasions: 145/90-196/90, E.C.G. normal, and chest X-ray normal.

At 10.30 A.M. morphine $10 \mathrm{mg}$. and atropine $0.4 \mathrm{mg}$. were given intramuscularly, and before induction at 11.45 he was awake and orientated with a systolic blood pressure of $160 \mathrm{~mm}$. $\mathrm{Hg}$ and pulse of 88 . Thiopentone $500 \mathrm{mg}$. was given slowly and anaesthesia continued with nitrous oxide, oxygen, and cyclopropane in a semiclosed circle absorption system. Succinylcholine 0.1 per cent was administered intravenously and artificial ventilation was used. During the ensuing 30 minutes the blood pressure rose to $280 / 120$ and the pulse to 120 . These cardiovascular signs preceded any other obvious evidence of ventilatory insufficiency or response to surgical stimuli. A diagnosis of phaeochromocytoma was dismissed at this time as unlikely and the patient was treated for hypercarbia, hypoxia due to emphysema, and mild bronchospasm. The soda lime was changed, patient intubated, artificial ventilation with a Jefferson ventilator (pressures $-5 \mathrm{~cm} . \mathrm{H}_{2} \mathrm{O}$-plus $20 \mathrm{~cm} . \mathrm{H}_{2} \mathrm{O}$ ) begun, meperidine $25 \mathrm{mg}$. given, and the cyclopropane discontinued. Ventilation was now improved but severe bronchospasm gradually developed: after $15 \mathrm{~min}$. the blood pressure had fallen to $220 \mathrm{~mm}$. $\mathrm{Hg}$ : a supraventricular tachycardia of $130 / \mathrm{min}$. and acute pulmonary oedema developed. This was treated by stopping the succinylcholine, of which $175 \mathrm{ml}$. had been used by this time, aspiration, reverse Trendelenburg tilt, cedilanid $1.6 \mathrm{mg}$. intravenously by intermittent injection, and voluntary respiration under ether anaesthesia. An hour later the pressure was $160 / 100$, pulse still 150, and the operation completed. E.C.G. showed a nodal tachycardia and quinidine $0.6 \mathrm{gm}$. was given intramuscularly. The blood pressure gradually decreased to $80 / 70$, but was maintained easily at approximately $115 / 70$ with an L-noradrenaline drip.

On the following morning the patient was conscious, orientated, and ventilating well: his blood pressure was $140 / 80$, but L-noradrenaline in small amounts was still necessary. E.C.G. was reported as a posterior wall myocardial infarct. During the day he became confused: the blood pressure was maintained, but death occurred forthy hours postoperatively.

Can. Anaes. Soc. J., vol. 8, no. 3, May, 1961 
At post-mortem examination there was no macroscopic evidence of brain damage and no evidence of myocardial hypertrophy or recent infarction. There was bilateral pulmonary congestion and oedema with superimposed early bronchopneumonia of hypostatic type. The right adrenal gland contained a phaeochromocytoma. Death is considered due to a phaeochromocytoma causing hypertension, left ventricular failure, and pulmonary oedema, followed by hypovolaemia and adrenal failure.

The causes of a sustained hypertensive response during anaesthesia may be considered in two groups: firstly, those that can be anticipated ard against which prophylactic measures taken and, secondly, those cases in which the response is anticipated merely as one of the possible complications of any anaesthetic. In the first group are patients suffering from phaeochromocytoma, thyrotoxicosis, transection of the spinal cord at or above $T 5$, or a raised intracranial pressure. Also included are those who have received a vasopressor and to whom an oxytocic drug has subsequently been administered, ${ }^{3}$ and those in whom the aorta has been clamped during the course of surgery.

The causes in the second 'group are more common and not infrequently act synergistically in the same case: 'Sensory stimuli during inadequate anaesthesia produce a pressor response even in the presence of 'hypovolaemia, though the blood volume must be within 20 -per cent of the patient's predicted normal. ${ }^{4}$ Clinical studies of cyclopropane anaesthesia have demonstrated a raised arterial pressure. ${ }^{5,6}$ This can occur with normal carbon dioxide levels and adequate depth of anaesthesia, ${ }^{7}$ though in one series ${ }^{5}$ hypercarbia was a constant finding. This in itself is associated with an increase in circulating catecholamines and a sustained elevation of pressure, the magnitude being unrelated to the increase in carbon dioxide tension. ${ }^{8,9}$ In the early stages of pulmonary oedema there are increases in pulse rate and arterial pressure, and the skin is usually cold and sweaty. ${ }^{2}$

There are now at least twenty-seven reported cases in which patients undergoing surgery for a variety of reasons were found to have had an unsuspected phaeochromocytoma. ${ }^{10-18}$ The anaesthesia was usually complicated by hypertension and pulmonary oedema. Twenty-three patients died within 48 hours postoperatively, frequently much sooner, and the diagnosis was made or confirmed at post-mortem examination.

The hazards of a sustained hypertension are that a cerebrorascular accident, cardiac failure, cardiac arrhythmia, or pulmonary oedema may occur. Also, it has been demonstrated in the experimental animal that raising the blood pressure can reflexly increase the bronchoconstrictor tone ${ }^{19}$ The pressor response is sometimes associated with a tachycardia which in itself is harmful. The ventricular filling time in diastole is reduced, lowering the cardiac output. The minute volume of any mitral regurgitation is increased and the competent right ventricle augments the volume of blood in the lungs, increasing the possibility of pulmonary oedema. Patients suffering from arteriosclerosis, mitral valvular disease, or pulmonary hypertension are especially prone to these ill effects. The toxic effects of adrenaline have been reviewed by Millar, ${ }^{20}$ and Szakacs ${ }^{21}$ and King ${ }^{22}$ have produced myocardial damage experimentally in dogs by the intravenous administration of $\mathrm{L}$-noradrenaline in clinical dosage. 
Treatment of a causative process is preferable to symptomatic treatment; and if the hypertension is considered with reference to the rate of development, peripheral circulation, ventilation, pulse rate, and other signs of autonomic activity, the cause may readily be determined. However, the degree and duration of hypertension that can be tolerated by a patient cannot be predicted with certainty, and possibly a sustained pressor effect for any reason during surgery plays a significant role in postoperative morbidity. In view of the hazards mentioned, it is advisable to take active steps to reduce a hypertension, when it occurs, even though the underlying cause cannot at the time be definitely decided. It is noteworthy that of the 27 reported cases of unsuspected phaeochromocytoma, three survivors ${ }^{11,13,14}$ were those for whom therapeutic measures had been directed primarily at correcting the pressor response and if these were unsuccessful the operation was abandoned.

Various drugs have been advocated for the prophylaxis or treatment of hypertension in anaesthesia under different circumstances: chlorpromazine, ${ }^{3,}{ }_{23},{ }_{24}$ hexamethonium, ${ }^{1,25,26}$ trimethaphăn,,$^{14}$ and phentolamine. ${ }^{10,13}{ }^{14}$ The following plan of campaign is suggested when, for reasons not fully understood, the systolic blood pressure rises at least $40 \mathrm{~mm}$. Hg above that normal for the patient, and maintains that level. If successful it should enable the operation ito be completed safely and the diagnosis of any additional pathology made during the convalescent period.

1. Ensure adequate ventilation but avoid a phase of negative pressure in the respiratory cycle at this time.

2. Reduce the rate of administration of intravenous fluids unless the patient is known to be hypovolemic with å healthy myocardium

3 . If there are confirmatory signs of inadequate anaesthesia, increase the concentration of the anaesthetic agent in use. In the absence of such signs, administer chlorpromazine $5-10 \mathrm{mg}$. intravenously and determine the effect of postural changes on the blood pressure.

4. If the blood pressure persists at the original high level, administer phentolamine $2-5 \mathrm{mg}$. intravenously and continue by intravenous infusion if' necessary. ${ }^{27},{ }^{28}$ This drug is used routinely for diagnostic purposes and for the treatment of hypertensive crises during the surgical removal of a phaeochromocytoma, but should be administered with caution. It has been postulated that a decreased red cell mass and chronic hypovolaemic state may be present in patients with phaeochromocytoma, and investigation of two patients substantiate this. Consequently, additional therapy required may be restoration of $\backslash$ the patient's blood volume. ${ }^{29}$

5. Supportive cardiac therapy with digitalis or prostigmine ${ }^{30,}{ }^{31}$ may now be considered. Only when the pressor response has been brought under control should consideration be given to using a negative pressure phase in artificial ventilation.

\section{SuMmary}

A case report of a 62-year-old man undergoing general anaesthesia for an inguinal herniorrhaphy is presented. Hypertension, bronchospasm, tachycardia, and pulmonary oedema developed during the procedure and the patient was 
treated for left ventricular failure. Death occured 40 hours postoperatively and a phaeochromocytoma on the right side was discovered at post-mortem examination. An account of the causes and significance of hypertension during anaesthesia is given: and a plan of treatment suggested for these cases in which the reason! for the pressor response is difficult to determine. This involves the assessment, of ventilation and depth of anaesthesia, use of chlorpromazine and phentolamine. Attention is drawn to the possible need for additional cardiovascular supportive therapy.

\section{RÉSUMÉ}

Nous avons présenté le cas d'un homme de 62 ans soumis à une anesthésie générale pour une opération de cure de hernie inguinale. Au cours de l'opération, il a présenté de l'hypertension, un bronchospasme, de la tachycardie et de l'œdème pulmonaire, puis ce malade a été traité pour insuffisance ventriculaire gauche. Il est mort quarante heures après l'opération et l'on a trouvé, à l'autopsie, un phéochromocytome droit. Nous avons émis des opinions sur les causes et la signification de l'hypertension au cours de l'anesthésie; nous suggérons une ligne de conduite pour traiter ces cas où il est difficile de préciser la raison de cette manifestation d'hypertension. Cela doit inclure une évaluation de la ventilation et de la profondeur de l'anesthésie et l'usage de la chlorpromazine et de la phentolamine. Nous attirons également l'attention sur la nécessité éventuelle d'appliquer une thérapeutique additionnelle pour supporter le système cardiovasculaire.

\section{REFERENCES}

1. Hale, Donald E. Blood Pressure in Anaesthesia. Current Res. in Anesth. and Analg. 85: 249 (1956).

2. Altschule, M. D. Acute Pulmonary Edema. New York: Grune and Sttatton (1954).

3. Casady, G. N., Moore, D. C., \& Bridenbaugh, L. D. Post Partum Hypertension after Use of Vasoconstrictor and Oxytocic Drugs. J.A.M.A. 172: 1011 (1960)

4. Grant, R. T., \& Reeve, E. B. Observations on the General Effects of Injury in Man. Medical Research Council Special Report-Series No. 277. Landon: H.M.S.O. (1951).

5. LI, T. H., \& Ersten, B. Effect of Cyclopropane Anesthesia on Cardiac Output and Related Hemodynamics in Man. Anesthesiology 18: 15 (1957).

6. Thompson, M. C., Patrick, R. T., \& Wood, E. H. Effects of Cyclopropane Anesthesia on the Circulation of Human Beings. J.A.M A. 164: 389 (1957).

7. Mclaughlin, G. Bleeding from Cut Skin and Subcutaneous Tissue Surfaces during Cyclopropane Anaesthesia. Brit. J. Anaesth. 26: 84 (1954).

8. Tenney, S. M. Mechanism of Hypertension during Diffusion Respiration. Anesthesiology 17: 768 (1956).

9. Bourne, Wesley. Effects of Excess Carbon Dioxide during Anesthesia. Current Res. in Anesth. and Analg. 35: 274 (1956).

10. Bartels, E. C., \& Catell, R. B. Pheochromocytoma: Its Diagnosis and Treatment. Ann. Surg. 181: 903 (1950).

11. Taylor, C., \& Stoelting, V. K. The Unsuspected Pheochromocytoma. J.A.M.A. 178: 753 (1960).

12. Lance, E. M.; Cate, W. R.; Liddle, G. W.; \& Scott, W. Clinical Experiences with Pheochromocytoma. Surg. Obst. Gynec. 106: 25 (1958).

13. Steen, T. R. Hypertension during Operation Anaesthesia 12: 80 (1957).

14. Walker, J. C. Ainley, \& Woodward, J. W. Acute Hypertension Developing under Anaesthesia near Fatality. Brit. J. Anaesth. $11: 167$ (1959). 
15. Crowther, K. V. Two Cases of Phaeochromocytoma, Brit. Med. J. i: 445 (1951).

16. Harrison, B. L., \& Seward, E. H. Pulmonary Oedema Due to Latent Phaeochromocytoma. Brit. Med. J. $i: 1077$ (1954).

17. Koonce, D. H., Pollock, B. E., \& Glassy, F. J. Phaeochromocytoma with Neurofibromatosis. Amer. Heart J. 44: 901 (1952).

18. Apgar, V., \& Papper, E. M. Phaeochromocytoma: Anaesthetic Management during Surgical Treatment. Arch. Surg. 62: 634 (1951).

19. Daly, M. DE B., \& Schweitzer, A. Reflex Bronchoconstrictor Responses to Stimulation of Receptors in the Regions of the Carotid Sinus and Arch of the Aorta in the Dog and Cat. J. Physiol. 118: 442 (1951).

20. Millar, R. A. Pharmacology and Phaeochromocytoma. Brit. J. Anaesth. 2950 (1957).

21. Szakacs, J. E., \& Cannon, A. L-Norepinephrine Myocarditis. Am. J. Clin. Path. 30: 425 (1958).

22. King, W. M., Brunson, J. G., \& Bieter, R. N. Cardiac Lesion\$ in Dogs following Administration of Pressor Amines. Circulation 18: 742 (1958).

23. Hunter, A. R. Chlorpromazine in Thyroid Cases. Lancet 269: 173 (1956).

24. Etsten, B., \& LI, T. H. Circulatory Effects of Chlorpromazine before and during Cyclopropane Anesthesia in Man. 'Anesthesiology 18: 203 (1957).

25. Riskin, A. M., Semeraro, D., \& Robertazzi, R. The Control and Management of Hyper-, tensive Crises Developing during Surgical Procedures. Anesthesiology 15: 262 (1954).

26. Ciliberti, B. J., Goldfein, J., \& Rovenstine, E. A. Hypertension during Anesthesia in Patients with Spinal Cord Injuries. Anesthesiology 15: 273 (1954).

27. Gifford, R. W., Roth, G. M., \& Kvale, W. F. Evalluation of a New Adrenalytic Drug as a Test for Pheochromocytoma. Ann. Surg. 194: 929 (1951)

28. Soffer, A. Regitine and Benodaine in the Diagnosis of Phebchromocytoma. Med. Clin. of N. Amer. 38: 375 (1954).

29. Bruntes, Johns V. I., \& Crane, M. G. Pheochromocytoma-Post operative Shock and Blood Volume. New Eng. J. Med. 262: 393 (1960).

30. Black, H., \& Harken, D. E. Safe Conduct of the Patient through Cardiac Surgery. New Eng. J. Med. 251: 45 (1954)

31. Middleton, H. G., \& Rendell-Baker, L. Anaesthesia and Coronary Artery Disease. Anaesthesia 15: 310 (1960). 